\title{
Flexible Poly(Vinyl Chloride)-Zeolite Composites for Dye Adsorption from Aqueous Solutions
}

\author{
DEVRIM BALKÖSE, ${ }^{*}$ SEVGI ULUTAN, and FEHIME ÖZKAN \\ DEPARTMENT OF CHEMICAL ENGINEERING \\ FACULTY OF ENGINEERING \\ EGE UNIVERSITY \\ BORNOVA, İZMIR, TURKEY
}

SEMRA ÜLKÜ

IZMIR INSTITUTE OF HIGH TECHNOLOGY

BASMANE, İZMIR, TURKEY

UĞUR KÖKTÜRK

DEPARTMENT OF MINING ENGINEERING

9 EYLÜL UNIVERSITY

BORNOVA, IZMIR, TURKEY

\begin{abstract}
Flexible poly(vinyl chloride) (PVC) composites having natural zeolite clinoptillolite were prepared by plastisol-plastigel technology. Adsoption of methylene blue on each raw material and on composites was studied both from an equilibrium and a rate approach. It was observed that the adsorption capacity of zeolite decreased when it was embedded in composites. The equilibrium uptake of methylene blue increased with an increasing zeolite fraction in composites. Methylene blue was adsorbed from a $0.02 \mathrm{~g} \cdot \mathrm{cm}^{-3}$ aqueous solution slowly, but was nearly adsorbed completely with a composite having a 0.3 volume fraction of zeolite. The effective diffusion coefficient of methylene blue in composites was of the order of $10^{-13} \mathrm{~m}^{2} \cdot \mathrm{s}^{-1}$ and decreased with increasing filler fraction.
\end{abstract}

\section{INTRODUCTION}

Poly(vinyl chloride) (PVC) plastisols are used in the production of coatings, films, sheets, foams, and rotational castings where the plastisol is

* To whom correspondence should be addressed. 
first spread on substrates and then heated to a gel and fuse (1). Leather substitutes were obtained by adding fillers such as synthetic silica or zeolites to the PVC-plasticizer system $(2,3)$. Animal ear tags were also made by the same method (4). In addition, silica prevented the plating out of PVC compounds during extrusion (5).

A 2-million ton reserve of natural zeolite clinoptillolite is spread over a $300-\mathrm{km}^{2}$ area in Bigadiç, Turkey (6). This reserve has recently been evaluated for use as an ion exchanger and as a gas and vapor adsorbent. Although it has a very high adsorption capacity, its mechanical strength is low for use as a column packing. Disintegration into smaller particles during repeated heating and cooling cycles plugs columns, so studies of pellet preparation from zeolites using a polymeric matrix have gained importance. Duval et al. (7) studied zeolite-filled glassy polymers. They reported the existence of three phases as polymer, zeolite, and voids in these composites.

The creation of composites with reproducible properties was difficult. While a gelation time of 2-3 minutes was sufficient for the primary particles of PVC, more than 40 minutes was required for complete penetration of plasticizer for the fusion of agglomerates (8).

In this study of emulsion-type PVC, dioctylphthalate (DOP) as plasticizer and natural zeolite clinoptillolite were chosen for the preparation of composites to be used as column packings. Methylene blue was chosen as a tracer to characterize the adsorptive properties of the composites from an environmental point of view. There are cases where methylene blue adsorption is irreversible on adsorbents such as anatase (9).

Solubility and the effective diffusion coefficient of an adsorbate in an adsorbent are two important variables in predicting column dynamics (10). Therefore the adsorption rates of methylene blue in composites were measured both from the concentration change in the aqueous phase and from the propagation of the colored front in the composites. Composites in the form of large and small pellets were prepared and contacted with methylene blue solutions.

\section{METHODS}

PVC (Petvinyl E 36/71), DOP (Sankim), and natural zeolite clinoptillolite [Bigadiç, Turkey, and characterized in previous studies $(11,12)]$ were used. Sixty parts DOP per 100 parts PVC were mixed in a Rowenta dough kneader to obtain the plastisol. Zeolite was added $(0.02$ to 0.3 volume fraction) and thoroughly mixed to obtain a homogeneous compound. 
Plate Preparation. Plastic plates of $2 \mathrm{~mm}$ thickness were obtained by casting the compounds in Petri dishes, deaerating in vacuum for 45 minutes, and heating at $160^{\circ} \mathrm{C}$ for 15 minutes.

Film Preparation. Plastic films of $100-300 \mu \mathrm{m}$ thickness were prepared from deaerated compounds by using a hot press. Fifty bar pressure was applied for 15 minutes at $140^{\circ} \mathrm{C}$.

Pellets. Six millimeter diameter pellets were cut both from plates and films with a paper perforator.

Adsorption Isotherm Measurements. Adsorption isotherms of methylene blue on PVC powder, zeolite powder, composites having no zeolite, and thick pellets with 0.3 volume fraction of zeolite were determined by measuring the equilibrium uptake from a $0.02 \mathrm{~g} \cdot \mathrm{dm}^{-3}$ methylene blue initial concentration at $25^{\circ} \mathrm{C}$. It was not possible to study the higher methylene blue concentration range due to the very dark color of the solutions. By changing the solid/liquid ratio, different equilibrium solution concentrations were obtained. The concentrations were measured by using a Jasco $7800 \mathrm{UV}$-visible spectrophotometer.

Solubility of Methylene Blue in DOP. Aqueous methylene blue solution and solid methylene blue powder were contacted with DOP separately and by vigorous shaking. The DOP phase was observed whether or not there was a color change due to methylene blue dissolution.

Adsorption Rate Experiments. The change of concentration of methylene blue solution in contact with either thick or thin pellets at a solid/liquid ratio of 0.007 was measured by visible spectroscopy. The initial concentration was $0.02 \mathrm{~g} \cdot \mathrm{dm}^{-3}$.

Visible Spectra of Films. Visible spectra of films as prepared and after equilibration with $0.02 \mathrm{~g} \cdot \mathrm{dm}^{-3}$ methylene blue solution were also obtained.

Optical Microscopy. Thin and thick pellets were examined using an Orthomat polarized microscope. Microphotographs of the horizontal cross sections of thick pellets were obtained using the transmission technique.

\section{RESULTS AND DISCUSSION}

\section{Equilibrium Studies}

\section{With Raw Materials}

Adsorption experiments of methylene blue on raw materials showed that it was adsorbed extensively on zeolite and moderately on PVC powder (Curves 1 and 2 in Fig. 1). Methylene blue was completely insoluble 


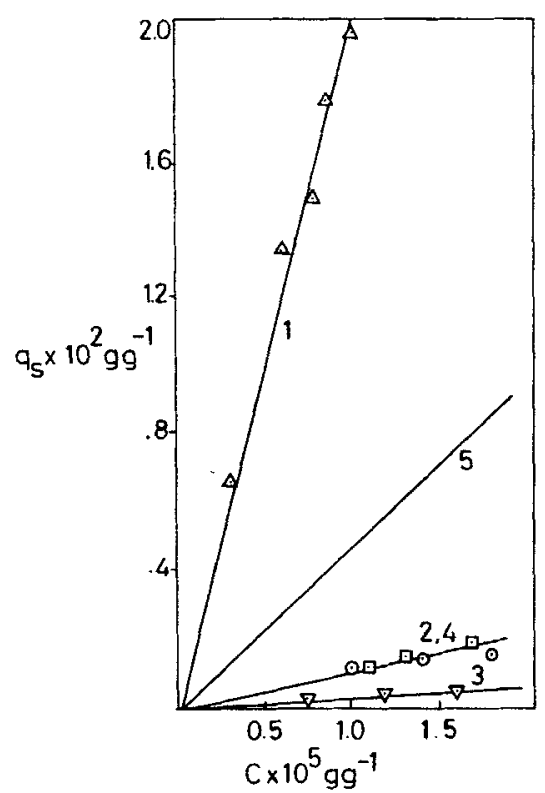

FIG. 1 Adsorption isotherms of methylene blue on (1) zeolite powder, (2) PVC powder, (3) PVC-DOP composite, (4) PVC-DOP-0.3 volume fraction zeolite composite, (5) predicted for PVC-DOP-0.3 volume fraction of zeolite composite from Eq. (2).

in DOP because no color change was observed in the DOP phase in contact with methylene blue.

\section{With Thick Pellets}

Pellets with no zeolites and 0.3 volume fraction of zeolites adsorbed methylene blue in minor and appreciable quantities, respectively (Curves 3 and 4 in Fig. 1). The insolubility of methylene blue in DOP and the complete solvation of PVC by DOP resulted in the inhibition of adsorption of methylene blue in composites with no zeolite.

Nearly all isotherms are linear (Nernst type) in the concentration range studied. The slopes of the isotherms in Fig. 1 are equilibrium constants, $K$, defined by

$$
q_{\mathrm{s}}=K c
$$

where $q_{\mathrm{s}}$ and $c$ are the weight fraction of methylene blue in the solid and solution, respectively, in $\mathrm{g} \cdot \mathrm{g}^{-1}$. The $K$ values shown in Table 1 show a 
TABLE 1

Linear Equilibrium Constants, $K$

\begin{tabular}{lr}
\hline Zeolite powder & 1800 \\
PVC powder & 110 \\
Composite with no zeolite & 40 \\
Composite with 0.3 volume fraction of zeolite & 110 \\
\hline
\end{tabular}

maximum (1800) for zeolite powder and a minimum (40) for a composite with no zeolite.

The adsorption capacities of the various components in composites are expected to be additive when there are no interactions among them (13, 14). If subscripts $c, 1$, and 2 stand for composite, matrix, and filler phases respectively, then

$$
K_{\mathrm{c}}=K_{1} w_{1}+K_{2} w_{2}
$$

where $w$ is the weight fraction in the composite. $K_{\mathrm{c}}$ was predicted as 480 from Eq. (2) for the composite with a 0.30 volume ( 0.25 weight) fraction zeolite composite. This was more than four times the experimentally observed value (110) shown in Table 1. The predicted and experimental $q_{\mathrm{s}}$ versus $c$ curves in Fig. 1 for 0.3 volume fraction zeolite indicated a smaller amount of dye was adsorbed than predicted from Eq. (2) at each solution concentration. This may be the result of either the interactions among DOP, PVC, and zeolite or the inaccessibility of the zeolite through the interphase between the PVC-DOP matrix and zeolite. Some voids may take place between the matrix and zeolite as observed recently by Duval et al. (7) for other polymer zeolite systems. The filling of the voids of the composite with the aqueous solution and the pores of zeolite by the liquid plasticizer should also be taken into consideration. Additionally, the insolubility of methylene blue in DOP may also hinder its transport onto zeolite.

The ratio of the equilibrium amount of dye in the solution to the equilibrium amount of dye in the solid $(\alpha)$ decreased with increasing volume fraction $(\Phi)$, as shown in Table 2 and Fig. 2. This indicates that the sites specific for adsorption of methylene blue are mainly on the zeolite fraction of the composites.

\section{With Thin Films}

The visible spectra of thin films before and after methylene blue adsorption (Fig. 3) showed the adsorption of the dye by the composite. While the original films were nearly transparent (Fig. 3a), methylene blue adsorbed films showed mainly the characteristic spectrum of methylene blue 
TABLE 2

$\alpha$ and $D$ Values Calculated from Solution Data and from Solid Data

\begin{tabular}{lllll}
\hline Volume fraction of zeolite, $\Phi$ & 0.00 & 0.10 & 0.16 & 0.30 \\
$\alpha$ & 4.0 & 1.85 & 1.50 & 0.33 \\
$D \times 10^{-13} \mathrm{~m}^{2} \cdot \mathrm{s}^{-1}$ from solution & - & 5.16 & 3.64 & 1.02 \\
$D \times 10^{-13} \mathrm{~m}^{2} \cdot \mathrm{s}^{-1}$ from solid & - & 3.08 & 2.22 & 1.30 \\
\hline
\end{tabular}

(Fig. 3b). Small changes in the spectra can be attributed to the chemisorption of methylene blue in composites. Absorbance at the $670 \mathrm{~nm}$ peak maximum versus the concentration of the zeolite in the composites, shown in Fig. 4, confirms the increase in methylene blue adsorption with zeolite volume fraction. Since color saturation occurs at high methylene blue concentration, the relationship between absorbance and methylene blue concentration deviates from linearity. Thus, it was not possible to obtain quantitative data about methylene blue concentration in composites.

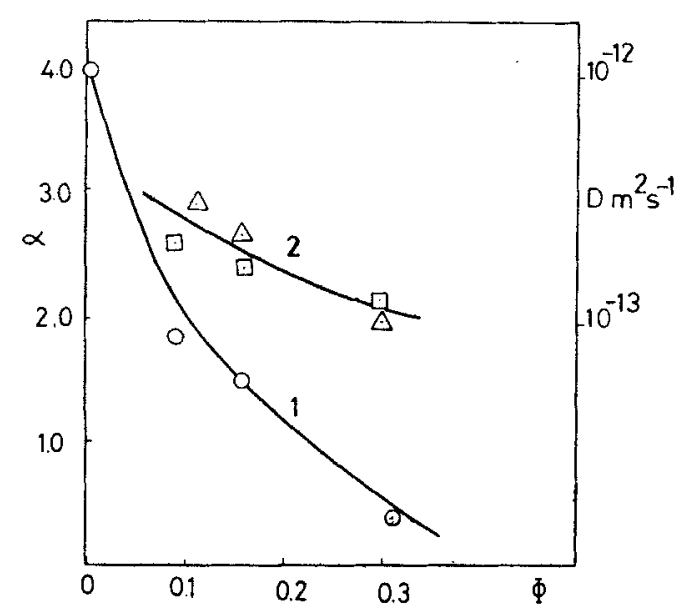

FIG. 2 Curve 1: The ratio of the equilibrium amount of dye remaining in solution to the amount of dye adsorbed on the pellets, $\alpha$, versus zeolite volume fraction of the composites $(\odot)$. Curve 2: Effective diffusion coefficient of methylene blue in composite versus volume fraction of zeolite, calculated from the solution $(\Delta)$ and calculated from the diffusion front in the solid ( $\boxminus$ ). 

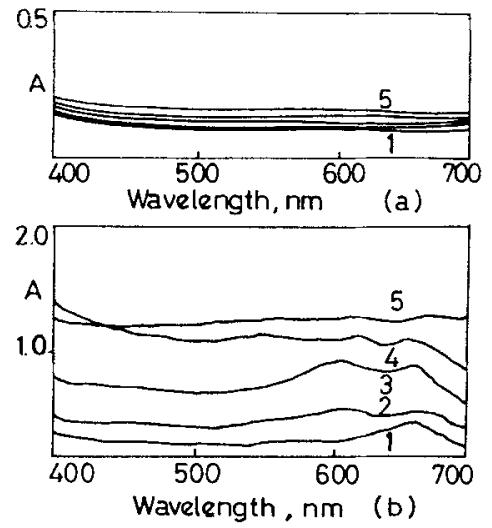

FIG. 3 Visible spectra of (a) as prepared and (b) methylene blue adsorbed thin films having (1) 0 , (2) 0.02 , (3) 0.05 , (4) 0.10 , and (5) 0.24 volume fractions of zeolites.

\section{Kinetic Studies}

\section{With Thick Pellets}

Diffusion from Solution Model. The concentration of $0.02 \mathrm{~g} \cdot \mathrm{dm}^{-3}$ methylene blue solutions decreases with increasing contact time with the composite pellets as shown in Fig. 5. Since the surface concentration changes with time, diffusion from the stirred solution of the limited volume model was used in calculating the effective diffusion coefficient of methylene blue in composites, $D$. The cylindrical sample geometry causes diffi-

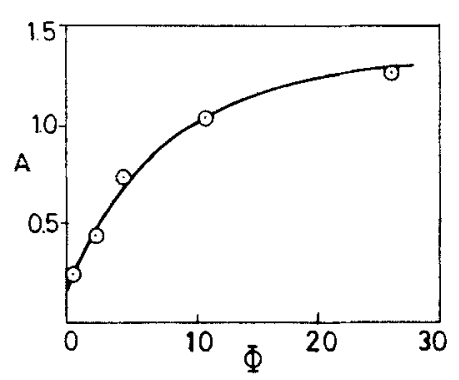

FIG. 4 Absorbance at $670 \mathrm{~nm}$ of the methylene blue adsorbed films versus volume fraction of zeolite, $\Phi$. 


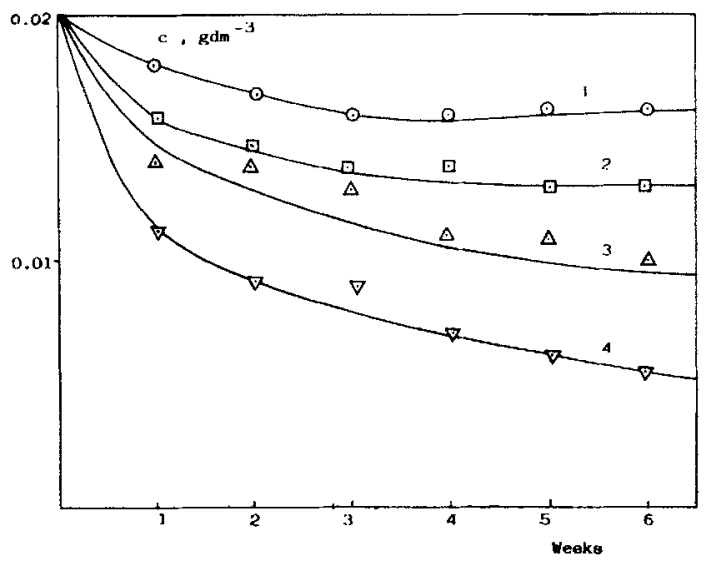

FIG. 5 Methylene blue concentration versus time for adsorption rate experiments for composites having $(1, \odot) 0.0,(2, \bullet) 0.1,(3, \Delta) 0.16$, and $(4, \nabla) 0.30$ volume fractions of zeolite.

culties in calculations. Although there exist analytical solutions for diffusion to an infinite cylinder, the 2-mm thickness of the pellets does not allow the use of this model. If the pellets are considered as thin membranes, the thickness/radius ratio of the pellets indicates that edge effects cannot be neglected. Thus, sacrificing the accuracy of the results just to see the tendency of the change of effective diffusion with the zeolite volume fraction, diffusion into plane sheet model (14) was chosen.

$$
M_{\mathrm{t}} / M_{\infty}=1-\Sigma\left[2 \alpha(1+\alpha) /\left(1+\alpha+\alpha^{2} q_{n}^{2}\right)\right] \exp \left(-D q_{n}^{2} t / l^{2}\right)
$$

where $q_{\mathrm{n}} \mathrm{s}$ are the nonzero positive roots of

$$
\tan q_{\mathrm{n}}=-\alpha q_{\mathrm{n}}
$$

and $l$ is half of the sheet thickness. Using proper $q_{\mathrm{n}}$ values for $\alpha$ values of this work, Eq. (3) was solved for the diffusion coefficient by the bisection method at each experimental data point. The average $D$ values with a standard deviation of $\pm 10 \%$, reported in Table 2 and shown in Fig. 2, are of the order of $10^{-13} \mathrm{~m}^{2} \cdot \mathrm{s}^{-1}$ and decrease with increasing zeolite volume fraction. Although the composite with no zeolite adsorbed a small quantity of methylene blue, it was not possible to measure the rate of adsorption from the very small change of solution concentration with time. Thus, the effective diffusion coefficient of the methylene blue in the composite with no zeolite could not be determined. 
From the Diffusion Front in the Solid Model. Drawings based on optical microphotographs of the cross sections of representative pellets (Fig. 6) indicated that while nonporous composites were prepared from DOP and PVC, composites with zeolites had spherical voids of various diameters. Although the same deaeration procedure was used for all the samples, the high viscosity of the zeolite added plastisols did not allow for the elimination of the entrapped air in PVC particles. The air expands during fusion of the plastisols and causes the formation of spherical bubbles in the final product.

The colored region thickness $(x)$ of all the pellets was measured from the optical microphotographs. It was not possible to observe the colored front of the composite with no zeolite due to the very small quantity of adsorbed methylene blue. The colored region thickness for the same contact time with the solution decreased as the zeolite fraction increased in the composites.

For practical reasons, the case can be treated as diffusion in a semiinfinite medium for constant surface concentration. The colored region thickness, $x$, is proportional to the square root of time:

$$
x=6(D t)^{0.5}
$$

The effective diffusion coefficient of methylene blue in the composites was calculated from the slope of $x$ versus $t^{1 / 2}$ plots (Fig. 7) using Eq. (5) and is shown in Table 2 and Fig. 2.

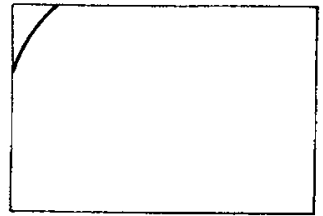

(a)

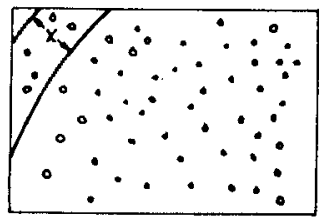

(c)
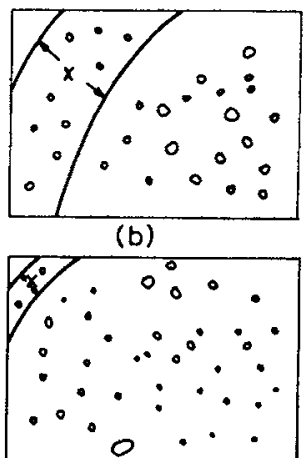

(d) $1 \mathrm{~mm}$

FIG. 6 Drawings from optical microphotographs of the horizontal cross-sections of the pellets of composites having (a) 0.0 , (b) 0.10 , (c) 0.16 , and (d) 0.30 volume fractions of zeolites and contacted with $0.02 \mathrm{~g} \cdot \mathrm{dm}^{-3}$ methylene blue solution for 22 hours. 


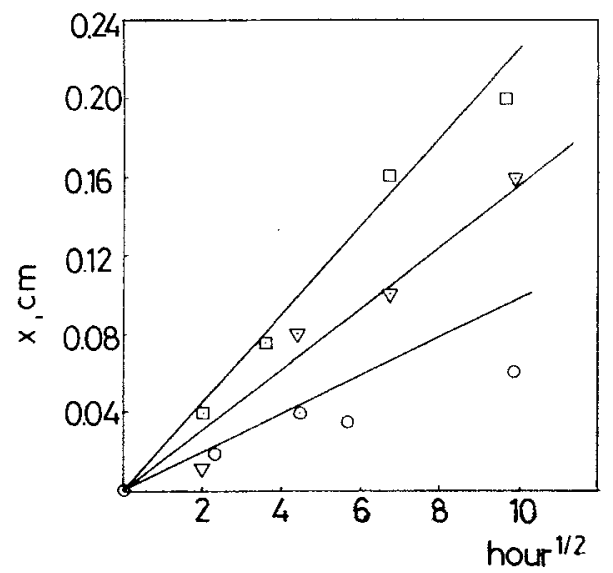

FIG. 7 Colored region thickness $(x)$ versus square root of time for thick pellets having $0.10(\square), 0.16(\nabla)$, and $0.30(\odot)$ volume fractions of zeolites.

The values of $D$ calculated from solution data using Eq. (1) and from solid data using Eq. (5) are very close to each other.

\section{With Thin Films}

It has not been possible to measure the colored region thickness of the thin films.

The effective diffusion coefficient of small molecules in porous solids depends on both the free volume (9) and the tortuosity factor of the solid. The presence of voids in composites makes a large contribution to the free volume. The strong localization of methylene blue in zeolites and the competition between DOP and methylene blue for active sites also affects the rate of adsorption of methylene blue from solution. The inaccessibility of the interphase between the zeolite and plastic matrix is another variable that affects $D$. The concentration dependence of $D$, as observed in other systems such as in agar gels (15), should also be taken into consideration. However, in the small range of methylene blue concentrations used in this study $\left(0-0.02 \mathrm{~g} \cdot \mathrm{dm}^{-3}\right)$, the diffusivity is assumed to be independent of concentration.

Although it was not possible to isolate the effect of each variable on the effective diffusion coefficient of methylene blue in composites, by treating the heterogeneous composites as homogeneous solids it was shown that it decreased with an increase in the zeolite filler fraction. 


\section{CONCLUSION}

Composites prepared by plastisol-plastigel technology from PVC$\mathrm{DOP}-$ zeolite are porous in structure. Although the reproducibility of preparing composites with this technique was low due to agglomeration of the particles and entrapped air, it was possible to obtain flexible plastics without using complicated machinery.

Equilibrium studies indicated that nearly complete removal of methylene blue was possible by using highly filled composites. On the other hand, kinetic studies indicated a slow rate of adsorption, which may be advantageous for keeping plastic articles made from composites intact in short contact times with water-soluble dyes.

$\alpha$ values of $0.33-4.00$ and $D$ values of $1.02 \times 10^{-13}$ to $5.16 \times 10^{-13}$ $\mathrm{m}^{2} \cdot \mathrm{s}^{-1}$ were observed for methylene blue adsorption in composites. While the equilibrium uptake increased, the uptake rates decreased with increased zeolite fractions.

By sacrificing some amount of the adsorption capacity of zeolites, it has been possible to prepare pellets with sufficient mechanical strength for column applications.

\section{REFERENCES}

1. N. Nakajima, M. R. Sadeghi, and T. Kyu, J. Appl. Polym. Sci., 41, 889 (1990).

2. Y. P. Watanuki, JP 01207345 (1986).

3. K. Fujii, JP 01279934 (1989).

4. V. Koralyi, HP 52133 (1990).

5. J. W. Maisel, Proceedings of Plastics Value through technology, SPE 44, Annual Tech. Conf. and Exhibit, 1990, p. 1215.

6. Y. Altav, A. Sirkecioğlu, and A. E. Şenatalar, Proc. First Turkish Chemical Engineering Congress, 1994, p. 86.

7. J. M. Duval, A. J. B. Kemperman, B. Folkers, M. H. V. Mulder, and G. Desgrandchamps, J. Appl. Polym. Sci, 54, 409 (1994).

8. S. Ulutan, H. Baltacioğlu, and D. Balköse, Eng. Syst. Des. Anal., 64(2), 153 (1994).

9. M. Zawadzki and A. W. Adamson, Fundamentals of Adsorption, New York, 1987, p. 619.

10. A. Rasmuson, Chem. Eng. Sci., 40, 621 (1985).

11. S. Ülkü, Stud. Surf. Sci. Catal., 28, 1047 (1986).

12. S. Ülkü, Z. Kivrak, and M. Mobedi, Proc. Drying 86, Hemisphere Publishing Co., Washington, D.C., 1986, p. 107.

13. G. S. Park, in Synthetic Membranes Science, Engineering and Applications (P. M. Bungay, Ed.), Riedel, London, 1986, p. 52.

14. J. Crank, The Mathematics of Diffusion, Clarendon Press, Oxford, 1975.

15. N. Rodrigues and N. E. Zaritzky, Int. Commun. Heat Mass Trans,, 10, 363 (1983). 